\title{
Características físico-químicas e microbiológicas da superfície do salame tipo italiano contendo solução de lactato de potássio
}

\author{
Physicochemical and microbiological characteristics of the surface of Italian salami containing potassium lactate
}

Alexandre José CICHOSKI ${ }^{1 \star}$, Luciana Cristina ZIS ${ }^{1}$, Carla FRANCESCHETTO ${ }^{1}$

\section{Resumo}

O objetivo do trabalho foi elaborar salame tipo italiano, substituindo parcialmente o $\mathrm{NaCl}$ por solução de lactato de potássio a $60 \%$ na razão de 0,75 e $1,5 \%$, e acompanhar, durante a etapa de permanência do produto dentro da câmara (zero, $2^{\circ}, 7^{\circ}, 14^{\circ}, 21^{\circ}$ e $30^{\circ}$ dia), algumas características físico-químicas (TBARS, $\mathrm{pH}$, umidade, $\mathrm{a}_{\mathrm{w}}, \mathrm{NO}_{2}$ ) e microbiológicas (bactérias lácticas, Micrococcaceae, Staphylococcus xylosus) na superfície do salame. Observou-se que nas superfícies dos salames que continham 1,5\% de lactato de potássio os valores de TBARS e o número de colônias das bactérias lácticas, Micrococcaceae e Staphylococcus xylosus, foram menores, enquanto os valores de umidade, $\mathrm{a}_{\mathrm{w}}$ e $\mathrm{pH}$, foram maiores do que os valores encontrados nas superfícies dos salames contendo $0,75 \%$ de lactato de potássio. A concentração de $1,5 \%$ de lactato de potássio apresentou ação antioxidante e tamponante, enquanto a concentração de $0,75 \%$ favoreceu o processo de desidratação e o desenvolvimento das bactérias lácticas, Micrococcaceae e Staphylococcus xylosus.

Palavras-chave: salame; superfície; lactato de potássio; bactérias; TBARS; pH; umidade.

\begin{abstract}
The aim of this work was the formulation of Italian salami with partial substitution of $\mathrm{NaCl}$ by a solution of potassium lactate $60 \%$ at concentrations of 0.75 and $1.5 \%$. Some physicochemical (TBARS, $\mathrm{pH}$, moisture, $\mathrm{a}_{\mathrm{w}}, \mathrm{NO}_{2}$ ) as well as microbiological characteristics (lactic bacteria, Micrococcaceae, Staphylococcus xylosus) were monitored on the surface of the salamis during storage (day zero, 2, 7, 14, 21, and 30). The results showed that on the surface of the salami prepared with $1.5 \%$ of potassium lactate the values of TBARS and the counting of lactic acid bacteria, Micrococcaceae and Staphylococcus xylosus were lower than the results found on the surface of salamis prepared with $0.75 \%$ of potassium lactate. On the other hand, the results of moisture, aw, and $\mathrm{pH}$ were higher on the surface of salamis with $1.5 \%$ of potassium lactate, than on the surface of salamis with $0.75 \%$ of the salt. The concentration of $1.5 \%$ of the lactate salt showed an antioxidant and buffering ability while the lower concentration favored the dehydration process and the growth of lactic bacteria, Micrococcaceae and Staphylococcus xylosus.
\end{abstract}

Keywords: salami; surface; potassium lactate; bacteria; TBARS; $p H$; moisture.

\section{Introdução}

Nos produtos cárneos fermentados a qualidade final e as características organolépticas, tecnológicas e microbiológicas são influenciadas pelo $\mathrm{pH}, \mathrm{a}_{\mathrm{w}}$, composição dos lipídios, $\mathrm{NO}_{2} \mathrm{e}$ $\mathrm{NaCl}$ (IBAÑEZ et al., 1995; QUINTANILLA et al., 1996).

Quando da elaboração da massa que vai ser empregada na fabricação do salame tipo italiano, adiciona-se entre 1,5 e 3,0\% de $\mathrm{NaCl}$. Embutida a massa, leva-se à câmara de maturação, onde permanece durante 30 a 40 dias, ocorrendo nesse período desidratação e aumento da concentração do $\mathrm{NaCl}$, que atinge valores entre 2,5 e 5,0\%. Esta concentração de $\mathrm{NaCl}$, somada ao baixo valor de $\mathrm{a}_{\mathrm{w}}$ e ao $\mathrm{pH}$ ácido, assegura a estabilidade dos salames fabricados, permitindo sua conservação em temperatura ambiente por muitas semanas (CHAGAS, 1998; VARNAM; SUTHERLAND, 1998).

As indústrias de produtos cárneos estão atualmente dando importância à quantidade de $\mathrm{NaCl}$ adicionada em seus produtos por sua relação com a hipertensão. Os sais empregados na substituição parcial do $\mathrm{NaCl}$ são $\mathrm{KCl}, \mathrm{MgCl}$ e $\mathrm{LiCl}$, mas apresentam restrições, uma vez que podem influenciar na qualidade sensorial dos produtos, conforme a quantidade utilizada (IBAÑEZ et al., 1995; IBAÑEZ et al., 1996).

A ingestão de sódio recomendada na dieta diária é de $1,5 \mathrm{~g}$, o que corresponde a $3,75 \mathrm{~g}$ de cloreto de sódio (COZZOLINO, 2005; SAH, 2007). O sal mais utilizado na substituição do cloreto de sódio é o cloreto de potássio, uma vez que o potássio exerce efeito anti-hipertensivo e apresenta ação protetora contra danos cardiovasculares (PEARSON, 1999). Entretanto, quando a substituição atinge níveis de 50\%, ocorre o aparecimento de sabor amargo e aroma metálico no produto e, nos produtos cárneos fermentados, pode promover alterações na etapa de fermentação, podendo ocorrer desenvolvimento de microrganismos indesejáveis (IBAÑEZ et al., 1995).

Recebido para publicação em 12/11/2007

Aceito para publicação em 14/4/2008 (003007)

${ }^{1}$ Curso de Engenharia de Alimentos, Universidade Regional Integrada - URI, Campus de Erechim, Av. 7 de Setembro, 1621, CEP 99700-000, Erechim - RS, Brasil,

E-mail: ajc@uricer.edu.br

${ }^{*}$ A quem a correspondência deve ser enviada 
Salames, nos quais foram substituídos 33\% de cloreto de sódio por cloreto de potássio, apresentaram valores de $\mathrm{pH}$, $\mathrm{a}_{\mathrm{w}}$ e contagens de bactérias ácido-lácticas semelhantes aos encontrados nos salames contendo somente cloreto de sódio, mas diferiram em relação ao conteúdo de $\mathrm{NO}_{2}$, que foi menor (IBAÑEZ et al., 1995).

A fermentação dos açúcares no salame tipo italiano é realizada pela ação de diferentes espécies de Lactobacillus homofermentativos adicionados à massa, produzindo ácido láctico (via Embden-Meyerhof) responsável pela queda do $\mathrm{pH}$, fato extremamente importante para a maturação desse produto. Podem também participar desta acidificação os Pediococcus e os Lactococcus (SHIMOKOMAKI et al., 2006).

As bactérias pertencentes à família Micrococcaceae comercializadas na forma de cultura pura são Staphylococcus xylosus, Staphylococcus carnosus e Kocuria varians, que promovem redução dos nitratos enquanto os níveis de ácido láctico ainda não estão muito elevados e o $\mathrm{pH}$ muito baixo, e apresentam também atividade lipolítica e proteolítica (QUINTANILLA et al., 1996; TERRA; FRIES; TERRA, 2004; SHIMOKOMAKI et al., 2006).

$\mathrm{O} \mathrm{NO}_{2}$ empregado nos produtos cárneos apresenta diversos efeitos associados às diferentes concentrações. Assim, concentrações entre 20 e $40 \mathrm{ppm}$ desenvolvem aroma no produto; entre 20 e $50 \mathrm{ppm}$ apresentam ação antioxidante; entre 30 e $50 \mathrm{ppm}$ desenvolvem cor; e entre 80 e $150 \mathrm{ppm}$ exercem efeito conservante no produto (TERRA; CICHOSKI; FREITAS, 2006).

Os lipídios são importantes ingredientes nos produtos cárneos fermentados, pois influenciam em suas características sensoriais, podendo no final do processamento representar $50 \%$ dos constituintes. Podem sofrer lipólise promovida pela ação das enzimas lipases de origem endógena ou microbiana (principalmente dos Staphylococcus), liberando ácidos graxos que poderão sofrer oxidações que poderão levar à rancidez, a qual reduzirá a vida útil desse tipo de produto, sendo esse considerado um grande problema (QUINTANILLA, 1996; VARNAM; SUTHERLAND, 1998; ORDÓÑEZ, 1999).

Pesquisas demonstraram que as atividades das enzimas lipases (endógenas e microbianas) diminuíam em concentrações altas de cloreto de sódio (STANHNKE, 1995; DOMINGUEZ; ZUMALACÁRREGUI, 1999), e que a rancidez aumentava devido ao cloreto de sódio tornar-se um pró-oxidante (VARNAM; SUTHERLAND, 1998; ORDÓÑEZ, 1999; ANDRADE, 2004).

O objetivo do trabalho foi elaborar salame tipo italiano, substituindo parcialmente o cloreto de sódio por solução de lactato de potássio a $60 \%$, na razão de 0,75 e $1,5 \%$, e acompanhar, durante a etapa de permanência do produto dentro da câmara (zero, 2, 7, 14, 21 e 30 dias), algumas características físicoquímicas (TBARS, $\mathrm{pH}$, umidade, $\mathrm{a}_{\mathrm{w}}, \mathrm{NO}_{2}$ ) e microbiológicas (bactérias lácticas, Micrococcaceae, Staphylococcus xylosus) na superfície dos salames.

\section{Material e métodos}

\subsection{Preparo das amostras}

Foram desenvolvidos três tipos de salames tipo italiano que foram divididos em Padrão (P) com 3\% de cloreto de sódio, Teste 1 (T1) com 1,5\% de cloreto de sódio e 1,5\% de solução de lactato de potássio a $60 \%$, e Teste 2 (T2) com 2,25\% de cloreto de sódio e $0,75 \%$ de solução de lactato de potássio a $60 \%$, correspondendo no Teste 1 a $0,90 \%$ de potássio e, no Teste 2, a $0,45 \%$.

A formulação empregada na elaboração dos salames continha $60 \%$ de carne suína, $30 \%$ de carne bovina, $10 \%$ de toucinho e cultura de Pediococcus pentosaceus e Staphylococcus xylosus (BACTOFERM T-SPX-100, da Chr Hansen, relação 25 g para $100 \mathrm{~kg}$ de massa). Os demais componentes foram calculados, levando-se em consideração somente a quantidade de carne suína e bovina, e suas quantidades foram: 0,3\% de $\mathrm{NaNO}_{2}$ (Cura para salame da Kraki); 0,25\% de eritorbato de sódio (Fixador A80-S, Kraki); $1 \%$ de condimento de salame tipo italiano (Kraki); e 1\% de sacarose. A carne bovina foi moída em disco de $5 \mathrm{~mm}$, e a carne suína em disco de $10 \mathrm{~mm}$, enquanto o toucinho foi cortado na forma de quadrados $(0,6 \times 0,6 \mathrm{~cm})$.

Misturados os ingredientes na massa de carne, procedeu-se ao embutimento da massa em tripa natural com calibre entre 35 a $40 \mathrm{~mm}$ (Kraki), previamente tratada em solução de ácido acético a $5 \%$ durante 30 minutos.

Os salames pesaram em média $670 \mathrm{~g}$ e apresentaram $40 \mathrm{~cm}$ de comprimento. Foram colocados dentro de uma câmara onde permaneceram durante 30 dias nas seguintes condições: $25^{\circ} \mathrm{C}$ e UR $95 \%$ no $1^{\circ}$ dia; $24^{\circ} \mathrm{C}$ e UR $92 \%$ no $2^{\circ}$ dia; $23^{\circ} \mathrm{C}$ e UR $89 \%$ no $3^{\circ}$ dia; $22^{\circ} \mathrm{C}$ e UR $86 \%$ no $4^{\circ}$ dia; $21^{\circ} \mathrm{C}$ e UR $83 \%$ no $5^{\circ}$ dia; $20^{\circ} \mathrm{C}$ e UR $80 \%$ no $6^{\circ}$ dia; $19^{\circ} \mathrm{C}$ e UR $80 \%$ no $7^{\circ}$ dia; e do $8^{\circ}$ dia até o $30^{\circ}$ dia a $18^{\circ} \mathrm{C}$ e UR $75 \%$.

\subsection{Métodos}

As análises físico-químicas e microbiológicas foram efetuadas logo após o embutimento (zero dia) e no $2^{\circ}, 7^{\circ}, 14^{\circ}$, $21^{\circ}, 30^{\circ}$ dia de permanência dos salames dentro da câmara, sendo coletadas amostras na superfície dos salames.

\section{Físico-químicas}

As análises físico-químicas de umidade e $\mathrm{pH}$ seguiram as metodologias descritas pela AOAC (2000); a determinação dos nitritos seguiu a metodologia descrita pelo IAL (1985). A atividade de água $\left(\mathrm{a}_{\mathrm{w}}\right)$ foi determinada no aparelho Aqualab modelo $\mathrm{CX}-2$, à temperatura de $30^{\circ} \mathrm{C}( \pm 0,1)$. A oxidação lipídica foi monitorada pelo TBARS, de acordo com a técnica de Tarladgis, Pearson e Ducan (1964), modificada por Crackel et al. (1988), seguindo as recomendações de Shahidi et al. (1985) no que se refere à adição de sulfanilamida para amostras que contêm nitrito e de teste de recuperação conforme descrito em Torres et al. (1989). 


\section{Microbiológicas}

Nas análises microbiológicas as amostras foram inoculadas através da técnica de semeadura em profundidade e incubadas a $30{ }^{\circ} \mathrm{C}$, durante 72 horas (STAHNKE, 1995). As bactérias pesquisadas foram as pertencentes à família Micrococcaceae, o Staphylococcus xylosus em meio agar mannitol salt (MAS) e as bactérias ácido lácticas em meio agar man rogosa e sharpe (MRS), com sobrecamada.

\section{Estatísticas}

Cada tipo de salame foi elaborado duas vezes, e as análises foram realizadas em triplicata. Os resultados foram analisados estatisticamente através dos cálculos das médias, desvio padrão, análise de variância e teste de Tukey $(\mathrm{p}<0,05)$ (CAMPOS, 1983).

\section{Resultados e discussão}

\subsection{Análises físico-químicas}

Os valores de TBARS obtidos na superfície dos salames pertencentes aos grupos Padrão, Teste 1 e Teste 2, logo depois de elaborados e durante o período de permanência de 30 dias dentro da câmara, encontram-se na Tabela 1.

Os salames pertencentes ao Teste 2 apresentaram os maiores valores de TBARS em todos os dias analisados, apresentando diferença significativa $(\mathrm{p}<0,05)$ em relação aos salames pertencentes ao Teste 1 e ao Padrão nesses dias (Tabela 1). Stanke (1993), Arnau, Guerrero e Sárraga (1998) e Dominguez et al. (1999) observaram que as atividades das enzimas proteases e lipases (endógenas e microbianas) diminuíam conforme aumentava a concentração de cloreto de sódio. Nos salames pertencentes ao Teste 2, foram adicionados 2,25\% de cloreto de sódio, e ocorreu maior índice de lipólise do que ocorreu nos salames pertencentes ao grupo Padrão, em que foi adicionado 3,0\% de cloreto de sódio e, consequentemente, ficou mais propício ocorrer oxidação, devido à maior quantidade de ácidos graxos liberados, demonstrando que em concentração de $0,75 \%$ a solução de lactato de potássio não apresenta efeito antioxidante, e que o efeito pró-oxidante do cloreto de sódio nessa concentração é maior (VARNAM; SUTHERLAND, 1998; ORDÓÑEZ et al., 1999; ANDRADE, 2004).

Fundamentando-se no mesmo princÍpio anterior, pode ser dito que nos salames pertencentes ao Teste 1 ocorreu maior índice de lipólise do que no Teste 2 e no Padrão, uma vez que a quantidade de cloreto de sódio era bem menor
(1,5\%), e a concentração de lactato de potássio (1,5\%) exerceu ação antioxidante, pois os valores de TBARS foram menores e diferiram significativamente $(\mathrm{p}<0,05)$ em relação aos valores apresentados pelo Padrão no $2^{\circ}, 7^{\circ}$ e $21^{\circ}$ dia de permanência dentro da câmara (Tabela 1). Mas esses salames em que foi substituído o cloreto de sódio por lactato de potássio, na proporção de 50\%, apresentaram sabor amargo, fato esse relatado por Ibañez et al. (1995).

Mesmo que o Teste 2 tenha apresentado no $30^{\circ}$ dia de processamento o maior valor de TBARS (1,24 mg, Tabela 1), esse valor não causaria danos à saúde do consumidor, pois, segundo Torres e Okani (2000), valores acima de 1,59 mg é que causam danos à saúde.

Os valores de $\mathrm{pH}$ obtidos na superfície dos salames pertencentes aos grupos Padrão, Teste 1 e Teste 2, logo depois de elaborados e durante o período de permanência de 30 dias dentro da câmara, encontram-se na Tabela 2.

Os maiores valores de $\mathrm{pH}$ ocorreram no Teste 1 , apresentando diferença significativa $(\mathrm{p}<0,05)$ em relação ao Teste 2 em todos os dias analisados e, em relação ao Padrão, somente no $30^{\circ}$ dia não ocorreu diferença significativa. No Teste 1 , a solução de lactato de potássio exerceu efeito tamponante, não permitindo que os valores de $\mathrm{pH}$ baixassem muito e principalmente atingissem valor próximo a 5,0, o qual indica que ocorreu uma boa fermentação (BUCKENHÜSKES, 1993), fato que aconteceu nos salames pertencentes ao Teste 2 e ao Padrão (Tabela 2).

Do $7^{\circ}$ dia de processamento em diante do salame tipo italiano, ocorreu aumento no valor de $\mathrm{pH}$, em decorrência das reações de descarboxilação e desaminação que ocorrem nos aminoácidos, as quais liberam amônia no meio, alcalinizando-o (ORDÓÑEZ et al., 1999). As superfícies dos salames pertencentes aos Testes 1 e 2 e ao Padrão apresentaram essa característica (Tabela 2), mesmo que os salames pertencentes ao Padrão e principalmente ao Teste 1 tenham apresentado valores de $\mathrm{pH}$ altos no final do processamento, estando estes bem acima dos valores encontrados em salames italianos comercializados no Brasil, cujos valores variaram entre 5,31 e 5,71 (CAVENAGHI; OLIVEIRA, 1999). Na superfície do salame, os valores de $\mathrm{pH}$ são maiores do que em sua parte interna, pois ocorre maior desidratação e, como consequência, tem-se maior quantidade de substâncias tamponantes formadas e aumento no grau de dissociação dos eletrólitos (VARNAM; SUTHERLAND, 1998).

Os valores de umidade obtidos na superfície dos salames pertencentes aos grupos Padrão, Teste 1 e Teste 2, logo depois

Tabela 1. Valores de TBARS obtidos na superfície dos salames tipo italiano pertencentes aos grupos Padrão, Teste1 e Teste 2, logo depois de elaborados e durante o período de permanência de 30 dias dentro da câmara.

\begin{tabular}{ccccrrr}
\hline TBARS $(\mathrm{mg} / \mathrm{kg})$ & Zero dia & $2^{\circ}$ dia & $7^{\mathrm{o}}$ dia & $14^{\mathrm{o}}$ dia & $21^{\circ}$ dia & $30^{\circ}$ dia \\
\hline Padrão & $0,087^{\mathrm{b}}( \pm 0,03)$ & $0,468^{\mathrm{b}}( \pm 0,02)$ & $0,605^{\mathrm{b}}( \pm 0,03)$ & $0,728^{\mathrm{b}}( \pm 0,02)$ & $0,914^{\mathrm{b}}( \pm 0,01)$ & $1,04^{\mathrm{b}}( \pm 0,01)$ \\
Teste 1 & $0,045^{\mathrm{b}}( \pm 0,01)$ & $0,416^{\mathrm{c}}( \pm 0,03)$ & $0,510^{\mathrm{c}}( \pm 0,02)$ & $0,633^{\mathrm{b}}( \pm 0,05)$ & $0,753^{\mathrm{c}}( \pm 0,01)$ & $1,00^{\mathrm{b}}( \pm 0,02)$ \\
Teste 2 & $0,412^{\mathrm{a}}( \pm 0,06)$ & $0,547^{\mathrm{a}}( \pm 0,01)$ & $0,838^{\mathrm{a}}( \pm 0,03)$ & $1,02^{\mathrm{a}}( \pm 0,06)$ & $1,09^{\mathrm{a}}( \pm 0,03)$ & $1,24^{\mathrm{a}}( \pm 0,02)$ \\
\hline
\end{tabular}

A temperatura dentro da câmara variou de $25^{\circ} \mathrm{C}$ para $18{ }^{\circ} \mathrm{C}$ e umidade relativa de $95 \%$ para $75 \%$. Salame Padrão $3 \%$ de $\mathrm{NaCl}$; Teste $11,5 \% \mathrm{NaCl}$ e $1,5 \%$ de solução de lactato de potássio a $60 \%$; Teste $22,25 \% \mathrm{NaCl}$ e $0,75 \%$ de solução de lactato de potássio a $60 \%$. a,bão analisados na vertical e letras diferentes apresentam diferença significativa pelo teste de Tukey (p < $0,05)$. 
de elaborados e durante o período de permanência de 30 dias dentro da câmara, encontram-se na Tabela 3.

Os salames pertencentes ao Teste 2 apresentaram os menores valores de umidade em relação aos valores encontrados no Padrão e no Teste 1, não ocorrendo diferença significativa $(\mathrm{p}<0,05)$ somente no $2^{\circ}$ dia de processamento. Os maiores valores de umidade foram encontrados no Teste 1 e também não ocorreu diferença significativa no $2^{\circ}$ dia de processamento em relação ao Padrão (Tabela 3). Os resultados obtidos em relação à umidade estão de acordo com os valores de $\mathrm{pH}$ apresentados pelo Teste 1, Teste 2 e Padrão (Tabela 2), em que o Teste 1 apresentou os maiores valores de $\mathrm{pH}$, enquanto o Teste 2 apresentou os menores valores.

O valor de umidade máximo permitido em salame tipo italiano é de 35\%, conforme o regulamento técnico de identidade e qualidade (BRASIL, 2000). Os salames pertencentes ao Teste 2 , entre o $14^{\circ}$ e $21^{\circ}$ dia de processamento, e os pertencentes ao Padrão, entre o $21^{\circ}$ e $30^{\circ}$ dia, apresentaram em sua superfície valores de umidade inferiores a 35\%, enquanto no Teste 1 isso não ocorreu durante todo o período analisado (Tabela 3).

Os valores de $\mathrm{a}_{\mathrm{w}}$ obtidos na superfície dos salames pertencentes aos grupos Padrão, Teste 1 e Teste 2, logo depois de elaborados e durante o período de permanência de 30 dias dentro da câmara, encontram-se na Tabela 4.

O Teste 1 apresentou os maiores valores de $\mathrm{a}_{\mathrm{w}^{\prime}}$ enquanto o Padrão apresentou os menores valores. A solução de lactato de potássio nas quantidades adicionadas, $0,25 \%$ no Teste $2 \mathrm{e}$ $1,5 \%$ no Teste 1 , influenciou nos valores de $\mathrm{a}_{\mathrm{w}}$ que apresentaram diferenças significativas $(\mathrm{p}<0,05)$ entre o Teste 1 e o Teste 2 , e de ambos em relação ao Padrão (Tabela 4). Ocorreu coerência entre os resultados obtidos de umidade (Tabela 3) no Teste 1, Teste 2 e Padrão, com os valores de $\mathrm{a}_{\mathrm{w}}$ apresentados, uma vez que o Teste 1 caracterizou-se por apresentar maior teor de umidade e também de $\mathrm{a}_{\mathrm{w}}$.

Valores de atividade de água inferiores a 0,93 são obstáculos ao desenvolvimento da grande maioria dos representantes da família Enterobacteriaceae, considerados indicadores higiênicos em presuntos curados (MARIN; CARRASCOSA; CORNEJO, 1996). Os salames pertencentes ao Padrão, Teste 1 e Teste 2, no sétimo dia de permanência dentro da câmara apresentaram valores inferiores a 0,93 dificultando assim o desenvolvimento de bactérias pertencentes à família Enterobacteriaceae (Tabela 4).

Staphylococcus aureus em condição aeróbica requer valor mínimo de $\mathrm{a}_{\mathrm{w}}$ para seu desenvolvimento de 0,86 (CHIRIFE; BUERA, 1986). A superfície dos salames pertencentes ao Padrão apresentou valor de $\mathrm{a}_{\mathrm{w}}$ inferior ao valor mínimo de desenvolvimento para Staphylococcus aureus já no $7^{\circ}$ dia; o Teste 2 a partir do $14^{\circ}$ dia; enquanto no Teste 1 isso ocorreu somente no $30^{\circ}$ dia de processamento (Tabela 4 ).

Mesmo que as superfícies dos salames pertencentes aos Tratamentos 1 e 2 tenham apresentado valores de $\mathrm{a}_{\mathrm{w}}$ maiores

Tabela 2. Valores de pH obtidos na superfície dos salames tipo italiano pertencentes aos grupos Padrão, Teste1 e Teste 2, logo depois de elaborados e durante o período de permanência de 30 dias dentro da câmara.

\begin{tabular}{ccccccc}
\hline pH & Zero dia & $2^{\mathrm{o}}$ dia & $7^{\mathrm{o}}$ dia & $14^{\mathrm{o}}$ dia & $21^{\circ}$ dia \\
\hline Padrão & $6,46^{\mathrm{b}}( \pm 0,01)$ & $5,12^{\mathrm{b}}( \pm 0,05)$ & $6,11^{\mathrm{b}}( \pm 0,01)$ & $6,34^{\mathrm{b}}( \pm 0,01)$ & $6,48^{\mathrm{b}}( \pm 0,01)$ & $6,69^{\mathrm{a}}( \pm 0,01)$ \\
Teste 1 & $6,71^{\mathrm{a}}( \pm 0,04)$ & $5,51^{\mathrm{a}}( \pm 0,01)$ & $6,18^{\mathrm{a}}( \pm 0,01)$ & $6,52^{\mathrm{a}}( \pm 0,01)$ & $6,79^{\mathrm{a}}( \pm 0,01)$ & $6,79^{\mathrm{a}}( \pm 0,01)$ \\
Teste 2 & $6,15^{\mathrm{c}}( \pm 0,02)$ & $5,11^{\mathrm{b}}( \pm 0,09)$ & $5,76^{\mathrm{c}}( \pm 0,01)$ & $6,22^{\mathrm{c}}( \pm 0,01)$ & $6,31^{\mathrm{c}}( \pm 0,01)$ & $6,31^{\mathrm{b}}( \pm 0,01)$ \\
\hline
\end{tabular}

A temperatura dentro da câmara variou de $25^{\circ} \mathrm{C}$ para $18{ }^{\circ} \mathrm{C}$ e umidade relativa de $95 \%$ para $75 \%$. Salame Padrão $3 \%$ de $\mathrm{NaCl}$; Teste $11,5 \% \mathrm{NaCl}$ e $1,5 \%$ de solução de lactato de potássio a $60 \%$; Teste $22,25 \% \mathrm{NaCl}$ e $0,75 \%$ de solução de lactato de potássio a $60 \%$. ${ }^{\mathrm{a}, \mathrm{b}}$ são analisados na vertical e letras diferentes apresentam diferença significativa pelo teste de Tukey $(\mathrm{p}<0,05)$.

Tabela 3. Valores de umidade obtidos na superfície dos salames tipo italiano pertencentes aos grupos Padrão, Teste1 e Teste 2, logo depois de elaborados e durante o período de permanência de 30 dias dentro da câmara.

\begin{tabular}{ccccccc}
\hline Umidade (\%) & Zero dia & $2^{\mathrm{o}}$ dia & $7^{\mathrm{o}}$ dia & $14^{\mathrm{o}}$ dia & $21^{\circ}$ dia & $30^{\circ}$ dia \\
\hline Padrão & $72,88^{\mathrm{a}}( \pm 1,10)$ & $70,68^{\mathrm{a}}( \pm 0,44)$ & $53,76^{\mathrm{b}}( \pm 0,55)$ & $49,85^{\mathrm{b}}( \pm 0,88)$ & $46,13^{\mathrm{b}}( \pm 0,22)$ & $32,19^{\mathrm{b}}( \pm 0,37)$ \\
Teste 1 & $72,93^{\mathrm{a}}( \pm 0,71)$ & $70,80^{\mathrm{a}}( \pm 0,63)$ & $66,86^{\mathrm{a}}( \pm 0,32)$ & $63,55^{\mathrm{a}}( \pm 0,51)$ & $62,80^{\mathrm{a}}( \pm 0,49)$ & $58,50^{\mathrm{a}}( \pm 1,11)$ \\
Teste 2 & $69,31^{\mathrm{b}}( \pm 0,79)$ & $68,98^{\mathrm{a}}( \pm 0,68)$ & $41,85^{\mathrm{c}}( \pm 0,78)$ & $36,19^{\mathrm{c}}( \pm 1,36)$ & $32,45^{\mathrm{c}}( \pm 0,64)$ & $30,00^{\mathrm{c}}( \pm 0,90)$ \\
\hline
\end{tabular}

A temperatura dentro da câmara variou de $25{ }^{\circ} \mathrm{C}$ para $18{ }^{\circ} \mathrm{C}$ e umidade relativa de $95 \%$ para $75 \%$. Salame Padrão $3 \%$ de $\mathrm{NaCl}$; Teste $11,5 \% \mathrm{NaCl}$ e $1,5 \%$ de solução de lactato de potássio a $60 \%$; Teste $22,25 \% \mathrm{NaCl}$ e $0,75 \%$ de solução de lactato de potássio a $60 \%$. a,bão analisados na vertical e letras diferentes apresentam diferença significativa pelo teste de Tukey $(\mathrm{p}<0,05)$.

Tabela 4. Valores de $\mathrm{a}_{\mathrm{w}}$ obtidos na superfície dos salames tipo italiano pertencentes aos grupos Padrão, Teste 1 e Teste 2, logo depois de elaborados e durante o período de permanência de 30 dias dentro da câmara.

\begin{tabular}{ccccccc}
\hline $\mathrm{a}_{\mathrm{w}}$ & Zero dia & $2^{\mathrm{o}}$ dia & $7^{\circ} \mathrm{dia}$ & $14^{\mathrm{o}}$ dia & $21^{\circ}$ dia & $30^{\circ}$ dia \\
\hline Padrão & $0,969^{\mathrm{c}}( \pm 0,01)$ & $0,956^{\mathrm{c}}( \pm 0,01)$ & $0,854^{\mathrm{c}}( \pm 0,01)$ & $0,820^{\mathrm{c}}( \pm 0,01)$ & $0,810^{\mathrm{c}}( \pm 0,01)$ & $0,707^{\mathrm{c}}( \pm 0,01)$ \\
Teste 1 & $0,981^{\mathrm{a}}( \pm 0,01)$ & $0,976^{\mathrm{a}}( \pm 0,01)$ & $0,917^{\mathrm{a}}( \pm 0,01)$ & $0,888^{\mathrm{a}}( \pm 0,01)$ & $0,867^{\mathrm{a}}( \pm 0,01)$ & $0,713^{\mathrm{a}}( \pm 0,01)$ \\
Teste 2 & $0,973^{\mathrm{b}}( \pm 0,01)$ & $0,968^{\mathrm{b}}( \pm 0,01)$ & $0,872^{\mathrm{b}}( \pm 0,01)$ & $0,839^{\mathrm{b}}( \pm 0,01)$ & $0,812^{\mathrm{b}}( \pm 0,01)$ & $0,710^{\mathrm{b}}( \pm 0,01)$ \\
\hline
\end{tabular}

A temperatura dentro da câmara variou de $25{ }^{\circ} \mathrm{C}$ para $18{ }^{\circ} \mathrm{C}$ e umidade relativa de $95 \%$ para $75 \%$. Salame Padrão $3 \%$ de $\mathrm{NaCl}$; Teste $11,5 \% \mathrm{NaCl}$ e $1,5 \%$ de solução de lactato de potássio a $60 \%$; Teste $22,25 \% \mathrm{NaCl}$ e $0,75 \%$ de solução de lactato de potássio a $60 \%$. ${ }^{\text {a,b }}$ são analisados na vertical e letras diferentes apresentam diferença significativa pelo teste de Tukey $(\mathrm{p}<0,05)$. 
que os do Padrão, no $14^{\circ}$ e no $7^{\circ}$ dia de processamento, respectivamente, ambos apresentaram valor de $a_{w}$ abaixo de 0,90 , que é o valor referência determinado pelo Regulamento Técnico de Identidade e Qualidade para salame tipo italiano (BRASIL, 2000).

As concentrações de $\mathrm{NO}_{2}$ obtidas na superfície dos salames pertencentes aos grupos Padrão, Teste 1 e Teste 2, logo depois de elaborados e durante o período de permanência de 30 dias dentro da câmara, encontram-se na Tabela 5.

$\mathrm{O}$ Teste 1 apresentou as maiores concentrações de $\mathrm{NO}_{2}$ do $14^{\circ}$ ao $30^{\circ}$ dia de processamento, diferindo significativamente $(\mathrm{p}<0,0,5)$ em relação ao Teste 2 , mas em relação ao Padrão a diferença ocorreu somente no $21^{\circ}$ e no $30^{\circ}$ dia (Tabela 5).

O Regulamento Técnico de Identidade e Qualidade do salame tipo italiano (BRASIL, 2000) recomenda que a concentração de $\mathrm{NO}_{2}$ residual máxima seja de $30 \mathrm{ppm}$. Desta forma, na superfície dos salames pertencentes ao Teste 2 , já no $21^{\circ}$ dia de processamento, a concentração de $\mathrm{NO}_{2}$ estava abaixo do limite máximo estipulado pelo regulamento, enquanto no Teste 1 e no Padrão isso ocorreu no $30^{\circ}$ dia de processamento (Tabela 5 ).

\subsection{Análises microbiológicas}

O número de colônias de bactérias lácticas $\left(\log _{10} \mathrm{UFC} \mathrm{g}^{-1}\right)$ obtidas na superfície dos salames pertencentes aos grupos Padrão, Teste 1 e Teste 2, logo depois de elaborados e durante o período de permanência de 30 dias dentro da câmara, encontram-se na Figura 1.

No Teste 2 o número de colônias de bactérias lácticas variou de $\log _{10} 6,84$ UFC.g ${ }^{-1}$ a $\log _{10} 8,83$ UFC.g ${ }^{-1}$, sendo esses números maiores e significativos $(\mathrm{p}<0,05)$ em relação aos apresentados pelo Teste 1 e pelo Padrão. O Teste 1 caracterizou-se por apresentar o menor número de colônias, as quais variaram de $\log _{10} 6,58$ UFC.g $g^{-1}$ a $\log _{10} 7,48$ UFC.g ${ }^{-1}$, não diferindo do Padrão no $2^{\circ}, 14^{\circ}$ e $21^{\circ}$ dia de processamento (Figura 1 ).

Bactérias lácticas apresentaram comportamento e número de colônias semelhantes em salames que continham 0,92\% de $\mathrm{KCl}$ e em salames que continham somente $\mathrm{NaCl}$ na quantidade de 2,73\% (IBAÑEZ et al., 1995). Ocorreu comportamento semelhante na superfície dos salames pertencentes ao Padrão $(3 \% \mathrm{NaCl})$ e ao Teste $1(1,5 \%$ de $\mathrm{NaCl}$ e $1,5 \%$ de solução de lactato de potássio a $60 \%$ ), mas no número de colônias isso não aconteceu, pois o Teste 1 apresentou contagens maiores, diferindo estatisticamente $(\mathrm{p}<0,05)$ no zero dia, $2^{\circ}, 7^{\circ}$ e $30^{\circ}$ dia de processamento (Figura 1).
O número de colônias das bactérias pertencentes à família Micrococcaceae $\left(\log _{10}\right.$ UFC.g $\left.{ }^{-1}\right)$ obtidas na superfície dos salames pertencentes aos grupos Padrão, Teste 1 e Teste 2, logo depois de elaborados e durante o período de permanência de 30 dias dentro da câmara, encontram-se na Figura 2.

O número de colônias das bactérias pertencentes à família Micrococcaceae no Teste 2 variaram de $\log _{10} 5,96 \mathrm{UFC} \mathrm{g}^{-1}$ a $\log _{10} 8,38$ UFC. ${ }^{-1}$, sendo esses maiores do $7^{\circ}$ dia de

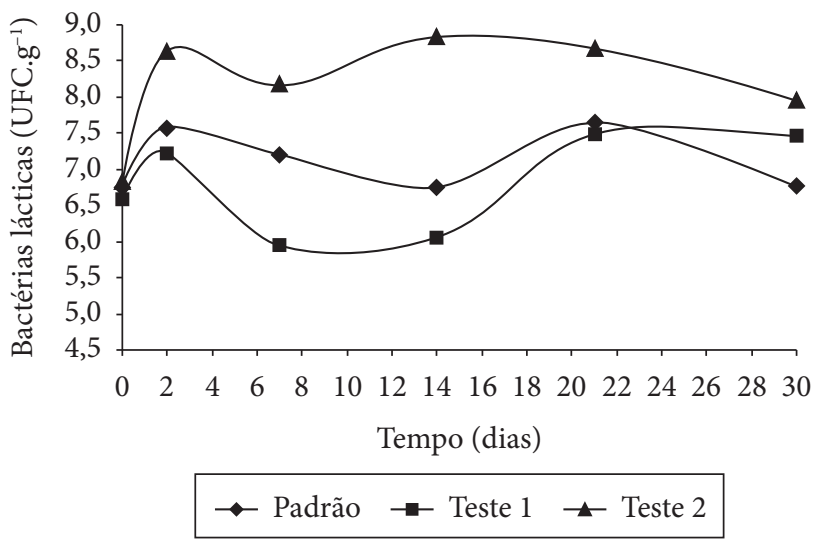

Figura 1. Número de colônias de bactérias lácticas $\left(\log _{10}\right.$ UFC.g $\left.^{-1}\right)$ obtidas na superfície dos salames tipo italiano pertencentes aos grupos Padrão, Teste1 e Teste 2, logo depois de elaborados e durante o período de permanência de 30 dias dentro da câmara.

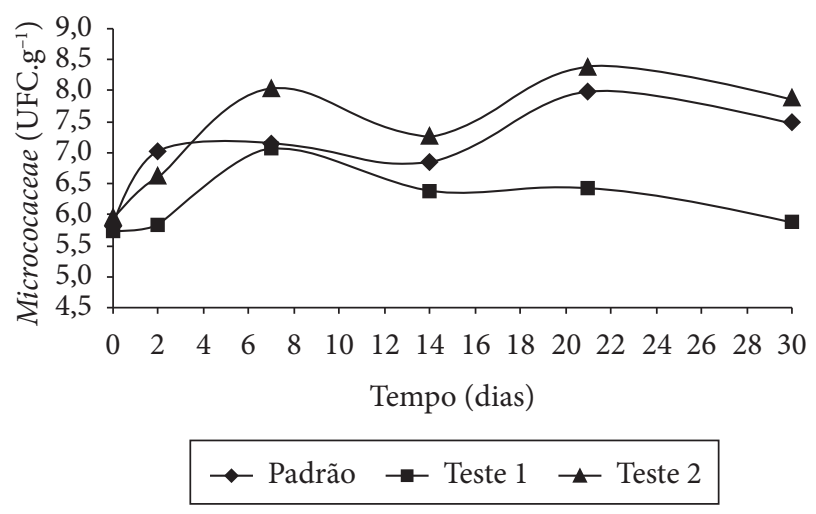

Figura 2. Número de colônias das bactérias pertencentes à família Micrococcaceae $\left(\log _{10}\right.$ UFC. $\left.g^{-1}\right)$ obtidas na superfície dos salames tipo italiano pertencentes aos grupos Padrão, Teste 1 e Teste 2, logo depois de elaborados e durante o período de permanência de 30 dias dentro da câmara.

Tabela 5. Concentrações de $\mathrm{NO}_{2}(\mathrm{ppm})$ obtidas na superfície dos salames tipo italiano pertencentes aos grupos Padrão, Teste 1 e Teste 2, logo depois de elaborados e durante o período de permanência de 30 dias dentro da câmara.

\begin{tabular}{|c|c|c|c|c|c|c|}
\hline $\mathrm{NO}_{2}(\mathrm{ppm})$ & Zero dia & $2^{\circ}$ dia & $7^{o} \mathrm{dia}$ & $14^{\circ}$ dia & $21^{\circ} \mathrm{dia}$ & $30^{\circ}$ dia \\
\hline Padrão & $129,09^{\mathrm{a}}( \pm 3,81)$ & $97,49^{\mathrm{a}}( \pm 1,79)$ & $83,95^{\mathrm{a}}( \pm 0,40)$ & $50,36^{\mathrm{a}}( \pm 4,10)$ & $35,59^{\mathrm{b}}( \pm 3,22)$ & $14,95^{c}( \pm 0,57)$ \\
\hline Teste 1 & $134,27^{\mathrm{a}}( \pm 1,29)$ & $89,37^{\mathrm{a}}( \pm 4,09)$ & $74,79^{\mathrm{a}}( \pm 8,64)$ & $50,89^{\mathrm{a}}( \pm 1,60)$ & $44,15^{\mathrm{a}}( \pm 2,93)$ & $26,02^{\mathrm{a}}( \pm 2,35)$ \\
\hline Teste 2 & $87,58^{\mathrm{b}}( \pm 4,8)$ & $95,74^{\mathrm{a}}( \pm 11,6)$ & $85,76^{\mathrm{a}}( \pm 5,7)$ & $42,97^{\mathrm{b}}( \pm 1,4)$ & $21,57^{\mathrm{c}}( \pm 3,0)$ & $20,39^{\mathrm{b}}( \pm 2,2)$ \\
\hline
\end{tabular}

A temperatura dentro da câmara variou de $25^{\circ} \mathrm{C}$ para $18{ }^{\circ} \mathrm{C}$ e umidade relativa de $95 \%$ para $75 \%$. Salame Padrão $3 \%$ de $\mathrm{NaCl}$; Teste $11,5 \% \mathrm{NaCl}$ e $1,5 \%$ de solução de lactato de potássio a $60 \%$; Teste $22,25 \% \mathrm{NaCl}$ e $0,75 \%$ de solução de lactato de potássio a $60 \%$. a,bão analisados na vertical e letras diferentes apresentam diferença significativa pelo teste de Tukey $(\mathrm{p}<0,05)$. 
processamento em diante, não diferindo estatisticamente ( $\mathrm{p}$ $<0,05)$ somente no $30^{\circ}$ dia em relação ao Padrão. No Teste 1 o número de colônias variou de $\log _{10} 5,74$ UFC.g ${ }^{-1}$ a $\log _{10}$ 7,06 UFC.g ${ }^{-1}$, caracterizando-se por apresentar os menores números de colônias, mas diferindo significativamente ( $\mathrm{p}<$ $0,05)$ do Padrão no $2^{\circ}, 14^{\circ}, 21^{\circ}$ e no $30^{\circ}$ dia de processamento (Figura 2).

Salames que continham $0,92 \%$ de cloreto de potássio a partir do $10^{\circ}$ dia de processamento apresentaram maior número de colônias de bactérias pertencentes à família Micrococcaceae do que o número de colônias encontradas nos salames que continham somente cloreto de sódio na quantidade de $2,73 \%$ (IBAÑEZ et al., 1995). Na superfície dos salames pertencentes ao Teste 2 (0,75\% de solução de lactato de potássio a $60 \%)$, do $7^{\mathrm{o}}$ dia de processamento em diante, o número de colônias das bactérias pertencentes à família Micrococcaceae foi maior do que o encontrado na superfície dos salames pertencentes ao Padrão, não diferindo estatisticamente $(\mathrm{p}<0,05)$ somente no $30^{\circ}$ dia (Figura 2).

O número de colônias de Staphylococcus xylosus $\left(\log _{10}\right.$ UFC.g $\left.{ }^{-1}\right)$ obtido na superfície dos salames pertencentes ao grupo Padrão, Teste 1 e Teste 2, logo depois de elaborados e durante o período de permanência de 30 dias dentro da câmara, encontra-se na Figura 3.

O maior número de colônias de Staphylococcus xylosus na superfície dos salames ocorreu no Teste 2 e variou de $\log _{10} 5,61$ UFC.g $g^{-1} \operatorname{alog}_{10} 7,37$ UFC.g ${ }^{-1}$, diferindo significativamente $(\mathrm{p}<0,05)$ em todos os dias analisados em relação ao número de colônias do Teste 1 , e no zero, $7^{\circ}$ e $21^{\circ}$ dia de processamento em relação ao Padrão (Figura 3). O Teste 1 apresentou um número de colônias que variou de $\log _{10} 5,10$ UFC.g ${ }^{-1}$ a $\log _{10} 6,42$ UFC.g ${ }^{-1}$, sendo que essas se caracterizaram por serem as menores, não diferindo significativamente $(\mathrm{p}<0,05)$ em relação ao número de colônias do Padrão $\left(\log _{10} 5,21\right.$ a $\left.\log _{10} 7,36\right)$ somente no $30^{\circ}$ dia de processamento (Figura 3 ).

Acompanhou-se o desenvolvimento da cultura de Staphylococcus carnosus em salames contendo 2,73\% de cloreto

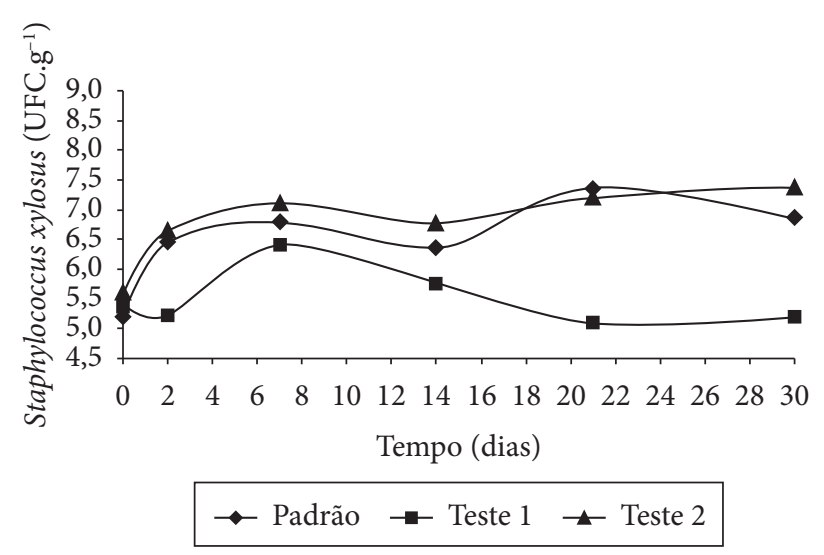

Figura 3. Número de colônias de Staphylococcus xylosus $\left(\log _{10}\right.$ UFC. $^{-1}$ ) obtido na superfície dos salames tipo italiano pertencentes aos grupos Padrão, Teste 1 e Teste 2, logo depois de elaborados e durante período de permanência de 30 dias dentro da câmara. de sódio e em salames contendo 1,37\% de cloreto de sódio e $0,92 \%$ de cloreto de potássio. O Staphylococcus carnosus desenvolveuse melhor no salame contendo $0,92 \%$ de cloreto de potássio, entre o $2^{\circ}$ e o $18^{\circ}$ dia de processamento (IBAÑEZ et al., 1996). A superfície dos salames pertencentes ao Teste 1 (1,5\% de solução de lactato de potássio ( $0,90 \%$ de potássio)) apresentou um número de colônias de Staphylococcus xylosus menor do que o encontrado no grupo Padrão, enquanto no Teste $2(0,75 \%$ de solução de lactato de potássio a $60 \%(0,45 \%$ e potássio $))$ o número de colônias foi maior do que no Padrão, no zero dia, $2^{\circ}, 7^{\circ}, 14^{\circ}$ e $30^{\circ}$ dia de processamento, não diferindo significativamente $(\mathrm{p}<0,05)$ no $2^{\circ}$ e $30^{\circ}$ dia (Figura 3 ), demonstrando que a concentração de potássio ao nível de 0,90\% inibe o desenvolvimento do Staphylococcus $x y$ losus e que em concentração de $0,45 \%$ isso não ocorre. Fato esse também observado nas bactérias lácticas (Figura 1), e nas bactérias pertencentes à família Micrococcaceae (Figura 2).

\section{Conclusões}

Nas superfícies dos salames que continham 1,5\% de solução de lactato de potássio, ocorreu menor índice de TBARS e maior valor de $\mathrm{pH}$, demonstrando que nessa concentração o lactato de potássio apresenta atividade antioxidante e ação tamponante.

Concentrações de lactato de potássio de 1,5 e 0,75\% não interferiram na quantidade final de $\mathrm{NO}_{2}$, nas superfícies dos salames.

As superfícies dos salames que continham $0,75 \%$ de solução de lactato de potássio apresentaram maior número de colônias das bactérias lácticas, Micrococcaceae e Staphylococcus xylosus e menor valor de umidade, demonstrando que nessa concentração o lactato de potássio favorece o processo de desidratação e o desenvolvimento das culturas puras adicionadas.

\section{Referências bibliográficas}

ANDRADE, B. C. E. et al. Comparação dos teores de cobre e zinco em leguminosas cruas e após serem processadas termicamente em meio salino e aquoso. Ciência e Tecnologia de Alimentos, v. 24, n. 3, p. 393-396, 2004.

Association Official Analytical Chemists - AOAC. Moisture and pH in meat. In: Official Methods of Analysis. 17 ed. Washington, 2000.

ARNAU, J.; GUERRERO, L.; SÁRRAGA, C. The effect of Green Ham $\mathrm{pH}$ and $\mathrm{NaCl}$ Concentration on Cathepsin Activities and the Sensory Characteristics of Dry-cured Hams. Journal Science Food Agriculture, v. 77, n. 3, p. 387-392, 1998.

BRASIL. Ministério da Agricultura e do Abastecimento. Regulamento Técnico de Identidade e Qualidade dos Produtos Cárneos. Instruções Normativas nº 20, 21 e 22, de 31 de Julho de 2000. Diário Oficial da União, Brasília, 3 de Agosto de 2000.

BUCKENHÜSKES, H. J. Selection criteria for lactic acid bacteria to be used as cultures for various food commodities. FEMS Microbiology Reviews, v.12, n. 1-3, p. 253-272, 1993.

CAMPOS, G. H. Estatística experimental não paramétrica. 4 ed. Piracicaba, São Paulo: ESALQ, 1983. 349 p.

CAVENAGHI, A. D.; OLIVEIRA, M. N. Influencia de algumas características físico-químicas e sensoriais na qualidade de salame tipo italiano fabricado no Brasil. Revista Nacional da Carne, v. 23, n. 263, p. 44-48, 1999. 
CHAGAS, S. S. Redução do Tempo de Fabricação do Salame tipo Italiano. Santa Maria, 1998. 99 p. Dissertação (Mestrado em Ciência e Tecnologia de Alimentos) - Universidade Federal de Santa Maria.

CHIRIFE, J.; BUERA, M. P. Water Activity, Water Glass Dynamics, and the Control of Microbiological Growth in Foods. Critical Reviews in Food Science and Nutrition, v. 36, n. 5, p. 465-513, 1996.

COZZOLINO, S. M. F. Biodisponibilidade de nutrientes. Barueri: Editora Manole Ltda, 2005. 878 p.

CRACKEL, R. J. I. et al. Some further observation on the TBA test as an index of lipid in meats. Food Chemistry, v. 28, n. 3, p. 187-196, 1988.

DOMÍNGUEZ, M. C.; ZUMALACÁRREGUI, J. M. Lipolytic and oxidative changes in "Chorizo" during ripening. Meat Science, v. 29, n. 2, p. 99-107, 1999.

IBAÑEZ, C. et al. Partial replacement of sodium chloride with potassium chloride in dry fermented sausages: Influence on carbohydrate fermentation and the nitrosation process. Meat Science, v. 40, n. 1, p. 45-53, 1995.

IBAÑEZ, C. et al. Dry fermented sausages elaborated with Lactobacillus plantarum - Staphylococcus carnosus. Part I: Effect of partial replacement of $\mathrm{NaCl}$ with $\mathrm{KCl}$ on the sataility and the nitrosation process. Meat Science, v. 44, n. 4, p. 227-234, 1996.

Instituto Adolfo Luz - IAL. Normas Analíticas. 3 ed. São Paulo,1985. $533 \mathrm{p}$.

MARÍN, M. E.; CARRASCOSA, A. V.; CORNEJO, I. Characterization of Enterobacteriaceae strains isolated during industrial processing of dry-cured hams. Food Microbiology, v. 13, n. 5, p. 375-381, 1996.

ORDÓÑEZ, J. A. et al. Changes in the components of dry-fermented sausages during ripening. Critical Riviews in Food Science and Nutrition, v. 39, n. 4, p. 329-367, 1999.

PEARSON, A. M. Curing. In: Processed meats. GaithersburgMaryland: Aspen Publication, 1999. p. 53-55.
QUINTANILLA, L. et al. Influence of partial replacement of $\mathrm{NaCl}$ with $\mathrm{KCl}$ on lipid fraction of dry fermented sausages inoculated with a mixture of Lactobacillus plantarum and Staphylococcus carnosus. Meat Science, v. 43, n. 3, p. 225-234, 1996.

Sociedade Americana de Hipertenção - SAH. Menos sal na dieta beneficia preção sangüínea. Disponível em: $<$ http://www.emedix. com.br/index.shtml>. Acesso em: Maio 2007.

SHAHIDI, E. et al. Effect of sulphanilamide on the TBA values of cured meats. Journal Food Science, v. 50, n. 1, p. 274-275, 1985.

SHIMOKOMAKI, M. et al. 2 Fementação cárnea. Princípios e Inovações. In: Atualidades em Ciência e Tecnologia de Carnes. São Paulo: Editora Livraria Varela, 2006. p. 29-36.

STAHNKE, L. H. Dried Sausages Fermented with Staphylococcus xylosus at Different Temperatures and with Different Ingredient Levels - Part I. Chemical and Bacteriological Data. Meat Science, v. 41, n. 2, p. 179-191, 1995.

TARLADGIS, B. G.; PEARSON, A. M.; DUCAN, Jr, L. R. Chemistry of the 2-tiobarbituric acid test for determination of oxidative rancity in foods. Journal Science Food Agricultury Champaing, v. 15, p. 602-607, 1964.

TERRA, A. B. M.; FRIES, L. M.; TERRA, N. N. Particularidades na fabricação de salame. São Paulo: Editora Livraria Varela, 2004. $152 \mathrm{p}$.

TERRA, N. N.; CICHOSKI, A. J.; FREITAS, R. J. S. Valores de nitrito e TBARS durante o processamento e armazenamento da paleta suína curada, maturada e fermentada. Revista Ciência Rural, v. 36, n. 3, p. 965-970, 2006.

TORRES, E. A. F. S. et al. Lipid oxidation in charqui (salted and dried beef). Food Chemistry, v. 32, n. 4, p. 257-268, 1989.

TORRES, E. A. F. S.; OKANI, E. T. Teste de TBA - Ranço em alimentos. [S.L.]: [s.n.], 2000. 10 p. (Trabalho original recebido do próprio autor, Departamento de Nutrição, Faculdade de Saúde Pública, Universidade de São Paulo - USP)

VARNAM, A. H.; SUTHERLAND, J. P. Embutidos fermentados. In: Carne y productos cárnicos. Zaragoza, Espanha: Editora Acribia, S.A., 1998. 